\title{
Familjen ur \\ barns perspektiv
}

\author{
GUNILLA HALLDÉN
}

\section{Hur berättar barn om familjeliv? En grupp barns texter på familjetemat analyseras utifrån hur maktrelationer, beroendeförhållanden och omsorg skildras. Berättandet} ses som ett sätt för barnen att undersöka sin egen position $i$ ett generations- och ett genussystem.

Vad är en familj? Vilka är dess kännetecken och vilken dess funktion? Är barn nödvändiga för att vi ska tala om familj? Och vilken roll har barnen i familjen? Familjebegreppet är problematiskt på många sätt och ges skilda betydelser beroende på sammanhang. Ofta används det liktydigt med hushåll. Barnfamilj kallar vi ett par med hemmaboende barn. Då barnen flyttat hemifrån är familjen inte längre en barnfamilj, trots att föräldrarna fortfarande har barn. Begreppet styvfamilj innebär att vi lägger till en annan specifisering till ordet familj och betecknar då en enhet som kan ha olika hushållsomfång vid olika tillfällen. Jan Trost har definierat familjen som en dyad (Trost 1993, 1994). Ett par som flyttar samman bildar en familj och denna familj ombildas då det föds barn. Dyaden utvidgas till en ny familj bestående av föräldrar och barn och denna fa-

Gunilla Halldén är docent i pedagogik och verksam vid pedagogiska institutionen, Stockholms universitet och vid tema Barn, Linköpings universitet. milj kan sedan ombildas vid skilsmässa och bestå av en förälder och barn. Familjemönstret kan se mycket olika ut och det finns inte fog för att tala om "kärnfamilj" som en nödvändig minsta beståndsdel innebärande att alla andra familjebildningar blir definierade som "splittrade familjer", "styvfamiljer", "enförälderfamiljer« eller "barnlösa familjerı, alltså avvikelser från normaliteten.

För att komma åt betydelser som kan ges åt familjen behöver vi beskrivningar från olika perspektiv; från vuxna och från barn, från kvinnor och från män, från pojkar och från flickor. Det finns både en generationsoch en genusaspekt på familjen och detta vill jag närmare undersöka i denna artikel. Datamaterialet jag använder utgörs av barns berättelser om sin fiktiva framtida familj. Hur berättar barn om familjeliv? Vilka scenarier och vilken rolluppsättning presenteras? Vad väljer barn att ta fasta på; dessa barn som växer upp i vår tid?

Via barnens berättelser får vi en möjlig- 
het att se hur de skapar begrepp och formulerar sig kring centrala teman. Det innebär också att vi betraktar dem som kapabla personer involverade i en socialisationsprocess som pågår hela livet och som inte verkar $p a ̊$ dem utan via dem. I sociologiska sammanhang har barn behandlats som en del av familjesociologin. Samtidigt finns risken att barnen aldrig ges en egen plats utan döljs i familjen. Familj blir synonymt med föräldrar. Jens Qvortrup har i olika sammanhang pekat på vikten av att lyfta fram en "sociology of childhood", med uppgift att beskriva barnens villkor (Qvortrup 1994 a och b). Barnen måste studeras i kraft av sin egen betydelse och inte som del i en familj. En anledning är att barnens viktiga erfarenheter inte alltid sker inom familjens ram och att de inte alltid lever under familjens kontroll. Ofta studeras familjen som en socialisationsarena, där barnet är mottagare av påverkan. Det är de vuxna som är urvalsenhet och det är deras agerande som studeras i relation till barnet. Även om man i olika forskningssammanhang är intresserad av barnen är de sällan studerade för sin egen skull.

Parallellt med sociologers hävdande av att barndom inte bara kan studeras som en del av familjesociologin, finns ett argumenterande mot den traditionella utvecklingspsykologin och socialisationsforskningen. Dessa forskningsområden anklagas för att ha den vuxna människan som norm. Barn studeras således som några på väg att bli vuxna. Det finns ett funktionalistiskt drag i denna tradition, där man intresserar sig för vägen till vuxen, i stället för att se barn som viktiga forskningsobjekt i sig. I forskningen om barndom, som något relevant också utanför utvecklingspsykologins och socialisa- tionsforskningens domäner, har man på senare år hävdat ett nytt paradigm för studiet av barndom (Prout \& James 1990). Barn ska studeras i sin egenskap av barn och inte som några som befinner sig på första etappen av en utvecklingsstege. Likartade perspektiv används av Barrie Thorne i hennes studie av skolbarns lek (Thorne 1993). Hon betraktar leken som ett sätt att iscensätta centrala frågor, där barnen använder lekramen ("vi leker barau, "det är bara på skoju) som en förklädnad för viktiga budskap relaterade till sexualitet och aggressivitet. I leken kan vi se hur barnen »do gender « för att använda Candace West och Don Zimmermans fras (West \& Zimmerman 1987). Gender är inte en egenskap eller något som utvecklas till en del av identiteten via socialisation. Det bör i stället ses som något som skapas i samspel och förhandlingar och som skiljer sig åt mellan olika kontexter, menar Barrie Thorne.

Det material jag bygger på här är insamlat vid ett skrivprojekt i en svensk lågstadieklass. ${ }^{1}$ Det kan rubriceras som en slags dockskåpslek på papper. Barnen, 32 stycken, 18 flickor och 14 pojkar, skrev och tecknade på temat "Min framtida familju under en två månadersperiod. Läraren diskuterade familjetemat och olika familjekonstellationer med barnen och uppmuntrade dem att fundera över ett framtida liv och möjliga livsformer. Som inledning ritade barnen det hus som de tänkte att de skulle bo i. Därefter tecknade de familjen de levde i och beskrev den. Berättelserna om familjen skapades genom att läraren ibland föreslog tema för berättelsen och bad barnen skriva om t.ex. »en

1 Projektet finansierades av Delegationen för social forskning och senare SFR. 
morgon", "vad gör vi på söndag?" eller "då blev jag besviken«. Andra gånger fick barnen skriva utifrån egna idéer. Husbilden plastades in och gjordes till framsida på den bok som bildades av barnens berättelser. Detta tillvägagångssätt innebar att berättandet gavs en ram och det underlättade en kontinuitet i skrivprocessen.

Hos vissa barn tycktes temat starta ett intensivt skapande med drag av rollspel, som kan tänkas ha haft en frigörande inverkan. Hos andra har berättandet inneburit svårigheter och texten är knapphändig och ibland svårtolkad. Alla barnen var emellertid engagerade i uppgiften och tog den på allvar. I någon mening såg de det som att de faktiskt skapade en familj åt sig. Det kan tyckas att uppgiften att berätta om livet i en tänkt framtida familj knöt an till en mamma-pappa-barn lek och på så sätt var designad för flickorna och mer främmande för pojkarna. Även om pojkarna inte var förtrogna med familjetemat via lek på samma sätt som flickorna, så innebar det emellertid inte att de visade mindre intresse för uppgiften. En episod kan illustrera detta. När barnen köade för lunch hörde läraren ett samtal som utspann sig mellan två av pojkarna. "Har du några barn?" frågade den ena pojken. Den andre såg frågande ut och fick tillägget „Ja, i din familj, menar jag?». »Ja, jag har två stycken", blev svaret. Pojken som frågat meddelade då att själv hade han en papegoja.

Berättelserna varierar i längd (mellan 5 sidor och 64 sidor), flickornas i större utsträckning än pojkarnas. Genomsnittslängden för pojkarnas berättelser är 10 sidor och om vi undantar de fyra längsta flickberättelserna blir genomsnittet för flickor- nas berättelser cirka 14 sidor. Det är svårt att ge rättvisa åt ett material av detta slag inom ramen för en artikel. Det skulle behövas längre utdrag ur berättelserna för att på ett riktigt sätt kunna belägga tolkningarna som görs. Jag väljer att här göra en tematisk analys av berättelserna och en textanalytisk. Det är också på sin plats att påpeka att jag medvetet valt att inte gå in i en diskussion av hur berättelserna förhåller sig barnens erfarenheter av sin egen familj. I detta sammanhang menar jag att det intressanta inte är att förklara varför barnen berättar på det sätt de gör, utan att analysera hur de berättar.

Det material som levereras via teckningar och berättelser kan inte avläsas som data om hur barnen upplever familjeliv eller data om vilken betydelse de tillmäter familjen. Det är fiktioner presenterade i en speciell kontext och via en stil anpassad till en genre av något slag. Kontexten är skolan, med en anpassning till läraren som är svår att undvika (vad får jag skriva om?). Och även om man beslutar att ingen av klasskamraterna ska få läsa berättelserna, finns alltid kamraternas ögon närvarande. De genrer som inverkar på berättandet kan vara familjeserier från TV, barnböcker, tecknade serier etc. Barnens teckningar och berättelser måste betraktas som barnens fiktion, en bild tecknad av drömmar, fantasier, förebilder och avskräckande exempel. Dessa fiktioner kan analyseras för att fånga vad man fokuserar när det handlar om familj, vad som är det centrala temat och mellan vilka personer viktiga händelser utspelar sig. De kan också analyseras utifrån hur författaren beskriver sig själv som agerande i berättelsen och hur relationer beskrivs. Jag får således data om barnens fiktion förmedlad i ett 
språk och inskriven i en tradition. Vad kan sägas om familjen, till vem och i vilket sammanhang? Det som presenteras är barnens perspektiv och deras fiktioner och stereotypier.

I berättelser av detta slag sker både ett beskrivande av den egna självbilden och ett formande av den. Som Bruner har påpekat i en artikel (Bruner 1991), innebär att skriva sin självbiografi eller att bli intervjuad om sitt liv att man berättar en historia, men att denna historia också kommer att återverka på hur man fortsättningsvis kommer att uppfatta sitt liv. Berättelser är i den meningen en version av verkligheten och ett sätt att skapa en delad värld, en intersubjektivitet. Berättelsens form är styrd av berättarkonventioner och en slags "narrative necessityu. På så sätt kommer vi att förstå verkligheten via de berättelser vi gör oss om verkligheten. "The central concern is not how narrative as text is constructed, but rather how it operates as an instrument of mind in construction of reality" (Bruner 1991, sid 5-6).

\section{Vem är centralgestalt?}

Vi kan sammanfatta innehållet i berättelserna som att flickorna skildrar ett familjeliv med interaktion mellan medlemmarna. I dessa familjer förekommer det ofta konflikter mellan barnen och mellan mamman och barnen. Den som fattar beslut och bestämmer i situationer av oenighet är huvudpersonen dvs den vuxna kvinnan. I pojkarnas berättelser förekommer inte alltid interaktion mellan familjemedlemmarna och det förekommer inte heller konflikter i så stor utsträckning som i flickornas berättelser.
Pojkarna ger inte sig själva rollen som den bestämmande vuxne personen i så stor utsträckning. Att besluten fattas av någon annan än huvudpersonen kan tolkas som uttryck för att pojkarna inte ger sig en central roll med maktbefogenheter. Det kan också tolkas som att de har ett skiftande alter ego. Det faktum att beslut fattas av barnen i flera av pojkarnas familjeberättelser kan ses som tecken för var berättarens solidaritet finns. Att låta partnern, farmor eller ett husdjur inneha beslutsmakt kan ses som ett sätt att placera sig själv i en underordnad position. Flickorna skildrar alltså sin huvudperson som en vuxen person med makt och omsorgsansvar, medan pojkarna inte alltid identifierar sig med den vuxne. Denne har heller inte alltid makten att bestämma.

Vi kan låta några citat från en flickas och en pojkes berättelser få illustrera skillnaden i sättet att positionsbestämma huvudpersonen. ${ }^{2}$ Anna berättar om sig själv som vuxen omhändertagande och ganska mäktig mamma till två döttrar. Fabian berättar om sig själv om far till två pojkar, men ger inte den vuxne rollen av konfliktlösare eller av omvårdande person. Anna berättar så här om en morgon:

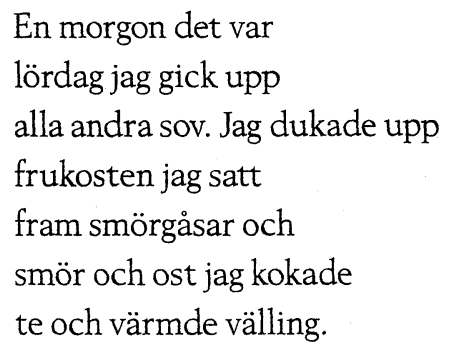

En morgon det var lördag jag gick upp alla andra sov. Jag dukade upp frukosten jag satt fram smörgåsar och smör och ost jag kokade te och värmde välling.

2 Barnen har här getts fingerade namn. Citaten återges ordagrant vad gäller stavning, interpunktion och radbrytning. 
Hon fortsätter med att berätta om konflikter som utbryter mellan barnen och som hon löser. Fabian skildrar en morgon på följande sätt:

En morgon gick Toben $i$

sömnen.

Nicklas virrade omkring i köket.

Och jag själv va i

mitt uppfinnarrum

och uppfinmde en pling plång

maskin.

I Annas berättelser är hon den som tar hand om allt och ibland undslipper hon sig ett suckande:

Det är torsdag
Sara och Sofie är
sjuka och det är
förstås jag som
måste vara ehmma
med dom så är
det nästan jämt

I Fabians berättelse är det komiska händelser som dominerar och motstridiga uppfattningar framställs, men utan att vi får veta utgången:

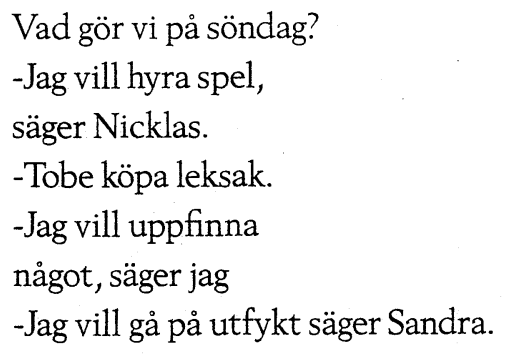

Detta avsnitt illustreras med ett slagsmål och pratbubblor som refererar till konflikten, men vi får inte veta utgången.

\section{Den starka modern närvarande hos flickorna, frånvarande hos pojkarna}

I flickornas berättelser finner vi alltså en kvinna i rollen som huvudperson och där markeras ansvar, omsorg och kontroll. Reproduktion som tema är centralt och det förekommer i flera berättelser att kvinnan föder barn, liksom att djuren gör det. Djurfödslar förekommer också hos pojkarna, däremot inte att barn föds.

I pojkarnas berättelser finns inte en stark och kontrollerande vuxen person. Hur ska vi förstå detta? Ett sätt att tolka berättelserna är att pojkarna i sina berättelser undviker just det som är centralt i flickornas, nämligen den starka och mäktiga modern? Är detta en så mäktig gestalt, att den inte kan beskrivas hos pojkarna. En del pojkar beskriver sitt framtida familjeliv utan en kvinna. En del låter henne vara med på bild, men sedan försvinna i texten. De flesta pojkarna skildrar emellertid ett familjeliv med mamma, pappa och barn, där livet består av olika rutiner, bråk med barn, liksom utflykter och fester, men utan den organiserande vuxne. Varken mamman eller pappan skildras då som organisatörer, utan livet levs antingen utan konflikter eller som ett kaos omöjligt att ordna.

Den oklara vuxenidentifikation, som förekommer hos en del pojkar, kan ses som sammanhängande med bristande skrivförmåga vilken försvårar ett konsekvent perspektiv. Det kan också ses som en ovilja att skriva om ett traditionellt familjeliv och att gå in i en mamma-pappa-barn lek. En intressantare tolkning är emellertid att se det som en influens av de genrer för familje- 
skildringar, som är förekommande i media. Det glada och lättsamma, liksom det ständigt gratifierande (via presenter och godis) skildras parallellt med det komiska och röriga. Pojkarna skildrar i någon mening familjelivet som ett liv för barn, inte ett liv för vuxna. Den fiktion som skapas av familjelivet, och som är beroende av detta genreval, innebär att man undviker makt- och kontrollfrågan. Pojkarna beskriver inte fadern som någon innehavare av makt och heller inte modern. Ibland kan kontroll undvikas och kaos kan få utbreda sig. Ett tumult och slagsmål kan utbryta, utan att någon vuxen ingriper eller att segraren utses. I andra fall uppstår aldrig konflikter, utan alla får sina önskemål tillfredsställda och i två fall skildras huvudpersonen som kontrollerad av en egensinnig papegoja.

I pojkarnas familjeskildringar är alltså den mäktiga modern frånvarande. Ett sätt för pojken att undvika modern, är att inte identifiera sig med en stark fader, någon som måste förhålla sig till modern. Modern är omöjlig att identifiera sig med, men också alltför hotfull att frondera mot. I stället hjälper genrevalet till att göra henne osynlig.

Hur ska vi då förstå flickornas berättelse? Är det så att flickorna leker en mammapappa-barn lek och fullföljer ett välbekant tema? Och ska vi i så fall tolka leken, som ett sätt att identifiera sig med mamman, den roll flickan själv en gång ska inta? Betyder det då att flickan redan är socialiserad till att ta hand om och att kontrollera och skapa ordning? Om vi hävdar att det som sker i skrivandet av dessa berättelser, är att barnen via genreinfluens, temaval etc. skapar en fiktion, blir den intressanta tolkningen att flickornas fiktion är den födande, närande och kontrollerande modern. En mäktig gestalt, som kan utforskas via ett rollspel. Någon som, med denna tolkning, är alltför hotfullt och främmande för pojkarna. Modern som den centrala gestalten är viktig för både pojkar och flickor. Flickorna väljer att utforska denna makt, pojkarna väljer att kringgå den.

Det som upptar stort utrymme i flickornas berättelser är beslutsfattande, dagliga rutiner, förhandlingar och lirkande med tredskande barn. I pojkarnas berättelser handlar det mer om utflykter, inköp av kapitalvaror som bilar och datorer eller av husdjur. Det finns ett vardagsliv och omvårdnad också hos pojkarna, men det har inte samma dominans som hos flickorna. Flickorna skriver om relationer, men de skriver också om makt och kontroll. Och pojkarnas berättelser är inte i första hand berättelser i avsaknad av relationer. Det är berättelser om inordning $i$ en grupp och ett skämtande med makten via regelbrott. Den lek, som skrivprojektet har intierat hos barnen, kan vi se som deras sätt att »do gender " (West \& Zimmerman 1987).

I den forskning som bedrivs av Gilligan och gruppen runt henne (se t.ex. Gilligan $m$ fl 1990, Brown \& Gilligan 1992) har man poängterat flickors sätt att värdera relationer. Flickors utveckling i vår kultur innebär, menar man, att flickor kommer att förbinda relationer med något centralt i livet, men också att de riskerar att tysta den egna rösten i rädsla för att ett värnande av egna behov hotar relationen till andra. Mitt datamaterial kan belysa denna problematik via en diskussion av hur temat reproduktion behandlas i berättelserna (Halldén 1993). Det ger också möjlighet att mer detaljerat granska hur makt 
och kontroll behandlas (Halldén under utgivning). En ytterligare aspekt rör skildringen av centrala aktörer och vilken position skribenterna ger sitt alter ego (Halldén 1994). Utöver en tematisk analys av materialet är det emellertid också intressant att diskutera berättarstil och genreinfluenser. Jag vill därför övergå till att diskutera berättelser som en del i ett samtal.

\section{Tiden och platsens betydelse $\mathrm{i}$ en familjeberättelse}

Vi kan betrakta en berättelse som styrd av berättarkonventioner, en slags "narrative necessity“ (Bruner 1991). Vem säger vad, till vem, i vilken situation? En berättelse är inte ett avtryck av en bestämd uppfattning, utan en "röst» $i$ betydelsen att den berättas för någon i en bestämd situation (Bakhtin 1937/1991). Den är influerad av en genre med bestämda formföreskrifter och står i dialog med andra berättelser. Den röst som talar i en berättelse utgör på det sättet en part $\mathrm{i}$ en dialog både med en tradition och en samtalskontext. Rösten bidrar samtidigt till formandet av den egna självbilden och den utforskar den egna positionen i ett kulturellt system. På samma sätt som det lilla barnet i leken utforskar centrala delar i tillvaron, utnyttjande kulturella mönster, så kan berättandet, skrivandet och tecknandet vara sätt att förstå, men via de konventioner och kulturella verktyg som är inbyggda i språket och i skilda förebilder. När barnen i denna studie berättar om en fiktiv familj kommer de att ansluta sig till en genre och de kommer att utnyttja denna genres regler för hur tid och plats knyts samman samt för vilka teman som lyfts fram. Att berätta blir, med detta betraktelsesätt, att involveras i en socialisationsprocess. Inte att via primäroch sekundärgruppspåverkan "bli socialiserad", utan att aktivt skapa sitt liv.

För att visa hur ett relations- och reproduktionstema ges form $i$ en berättelse vill jag utgå från en pojkes berättelse om sitt liv med husdjur. Som tidigare nämnts är det i flickornas berättelser som relationstemat är tydligast utformat, men det finns också hos pojkarna och i detta sammanhang kan det vara intressant att lyfta fram ett något udda familjescenario. Detta är inte en traditionell familjeskildring, men den använder samma sätt att koppla ihop tid och rum som görs i familjeromanen, som Bakhtin beskrivit (ibid.). Tiden skildras via förändringar på en plats och via ett markerande av gränsen mellan familjen och yttervärlden. Bakhtin använder sig av begreppet kronotop för att markera sättet som tid materialiseras i rummet. I familjeromanen, menar Bakhtin, understryks den cykliska tiden av den bestämda platsen, där livet utspelar sig, av en markering av sambandet mellan natur och människa samt av reproduktionen. Kronotopen manifesteras via platsen/huset, den mänskliga kroppen och det starka sambandet mellan barn och mat. Det finns ett idylliskt inslag, men också en markering av förändring. Gränsen mellan det säkra och det osäkra är viktig och introduceras i berättelsen via tröskelkronotopen; händelser som pekar ut gränsen och möjliggör överskridande.

Bill, vi kan kalla honom så, använder några få ord för att anlägga scenen:

"Mitt hus är en stuga

jag bor på en trädgård

jag har en flagstång." 
Familjen presenteras i en teckning föreställande Bill och hans tax, men de beskrivs aldrig i text. Berättelsen kan delas upp i sex scener, som alla behandlar ett vardagsliv. Det börjar emellertid med en ovanlig händelse. Som i sagorna är det en främmande person som träder in i familjesfären och åstadkommer en förändring. Bills stil är koncentrerad och effektfull. Med små medel anger han förändringen i familjen.

„En morgon så hörde
jag någonting när
jag åt frukost
det var nån som
krafsade på min dörr
jag gick och öppna
dörren där såg jag en
hund det var en chefer
det var en han
å han var smutsig
jag tog in honom
jag tvättade honom
sen gav jag honom
hundmat det gick
nảgra månader
min tax fick valpar."

Här använder Bill det som Bakhtin betecknar som en tröskelkronotop, för att markera förändringen i familjen. Någon skrapar på dörren. Dörren separerar de två sfärerna och den som träder över tröskeln kommer att förändra livet i den inre sfären. Schäfern är en främling, han är hungrig och smutsig. Bill tar hand om honom och làter honom bli en del av familjen. Könet markeras, "det var en han" och det visar sig vara betydelsefullt för händelseförloppet "det gick några månader min tax fick valpar». Detta är familjeromanens kronotop. Hemmets säkerhet understryks av kontrasten som främlingen utgör. Denna smutsiga och hungriga främling tas om hand och erbjuds plats i familjen. Inträdet kommer också att innebära födsel och en markering av reproduktion och tidens gång.

Bill beskriver vardagslivet i två episoder; i den ena episoden planerar han för en ledig dag och i den andra ger han sina hundar mat samt får post (något som visserligen är budskap från världen utanför familjen, men vars innehåll är trivialt). När Bill skriver på temat "då blev jag besviken" är han bekymrad över att hundarna är försvunna. Han letar över hela huset tills han till slut finner dem utanför huset. Här är det först en ängslan och oro och sedan en befrielse. Detta är en markering av vilka som hör ihop och bör finnas på plats samt av huset som centralt rum och yttervärlden som ett möjligt hot.

Efter besvikelsetemat följer två tämligen händelselösa episoder där Bill i ena fallet har stannat hemma från arbetet på grund av att han är dålig och i andra fallet firar påsk och får ett påskägg från en arbetskamrat. Här är familjesfären ställd mot arbetslivet/ offentliga sfären. Bill avslutar sin berättelse med en markering av tid och av familjelivets förändring.

"det gick några år mina
valpar blev stora
hundar och dom kanse
klarar sig ensama"

Detta är en uppföljning av inledningen med främlingens inträde. När Bill här avslutar sin familjeberättelse har det förflutit en tid och han reflekterar över vad det innebär för hans uppgifter av omhändertagande. Valparna blir här betraktade som barn som växer upp och så småningom kan klara sig själva och flytta ut från familjen.

Fastän Bill inte beskriver ett traditionellt 
familjeliv bestående av partner och barn, är det en familjeberättelse som utnyttjar familjeromanens sätt att knyta samman tid och rum och markera övergångarna mellan familj och yttervärld via tröskelkronotoper. Vi har hemmet/den bestämda platsen, vi har en förhållandevis lång tidsperiod och vi har banden som knyter samman familjemedlemmarna. Här finns hot från yttervärlden och huvudpersonens förmåga att hantera detta hot liksom förmågan att visa omsorg och sörja för ett uppväxande släkte. Familjeliv innebär förpliktelser mellan människor, en omvårdnad inriktad på reproduktion och en förändring över en tidsperiod.

\section{Barnperspektiv och genusperspektiv}

Syftet i denna artikel, har varit att fånga barns föreställningar om familjerelationer via deras berättande. Vad jag har diskuterat är förekomsten av olika tema i flickornas och pojkarnas berättelser, skildringen av centrala aktörer och positionen för berättarens alter ego. Jag har också diskuterat hur berättartraditioner och konventioner för att knyta samman tid och rum används. Vi kan konstatera att flickorna $\mathrm{i}$ större utsträckning än pojkarna markerar en maktposition för kvinnan/huvudperso- nen. Pojkarnas berättelser kringgår den starka kontrollerande föräldrafiguren och ger därmed större makt åt barnen. Ur ett generationsperspektiv innebär detta att pojkarna skildrar familjeliv som ett liv för barn, medan flickorna skildrar familjeliv som ett liv där barn hamnar i beroendeställning. Ur ett genusperspektiv innebär det att flickorna utforskar makten hos kvinnan i hennes egenskap av ansvarig för reproduktionen, medan pojkarna skämtar med makten genom att skildra ett smått kaotiskt familjeliv. Samtidigt kan vi konstatera att det finns variationer inom pojkberättelserna och flickberättelserna och att omsorg och ett ansvar för andra under en längre period kan behandlas på oika sätt.

I analysen av familjescenarier kan vi komma åt något av barnens sätt att förhålla sig till familjen och de maktrelationer och beroendeförhållanden som den förbinds med. Berättelserna kan läsas som fiktioner, där den egna positionen prövas. En undertext hos både flickorna och pojkarna är familjen som en arena där olika relationer av omsorg, kontroll, lek och expansivitet prövas. Familjetemat aktualiserar förbindelser mellan människor och gränser mot det okända, som både skyddar och är möjliga att överskrida. 


\section{Referenser}

Bakhtin, M. (1937/1991) The Dialogical Imagination. Four Essays by M.M. Bakhtin Austin: University of Texas Press.

Brown, L.M. \& Gilligan, C. (1992) Meeting at the Crossroads. Women's Psychology and Girls' Development Cambridge: Harvard University Press.

Bruner, J. (1991) »The narrative construction of reality", Critical Inquire, 18, 21.

Gilligan, C. m.fl. (1990) Making Connections. The Relational Worlds of Adolescent Girls at Emma Willard school Cambridge: Harvard University Press.

Halldén, G. (1993) „Reproduction the essence of family life?", Family Life and Social Control. Discourses on Normality, konferensrapport från Social Science Research Unit, Institute of Education, University of London.

Halldén, G. (1994) „Establishing order. Small girls write about family life", Gender \& Education, 6, 1, sid 3-17

Halldén, G. (under utgivning) »The family - a refuge from demands or an arena for the exercise of power and control. Children's fictions on their future families". Mayall, B. (red.) Children's Childhoods, London: Falmer.

Prout, A. \& James, A. (1990) "A new paradigm for the sociology of childhood? Provenance, promise and problems", James, A. \& Prout, A. (red.) Constructing and Reconstructing Childhood; Contemporary Issues in the Sociological Study of Childhood, London: Falmer.

Qvortrup, J. (1994 a) „Childhood matters: an introduction", Qvortrup, J. et al. (red.) Childhood Matters: Social Theory, Practice and Politics, Averbury: Aldershot.

Qvortrup, J. (1994 b) Recent Development in Research and Thinking on Childhood, paper presenterat vid Children \& Families: Research and Policy, konferens i London 28-30 april.

Thorne, B. (1993) Gender Play. Girls and Boys in School, Buckingham: Open University Press.

Trost, J. (1993) Familjen i Sverige, Stockholm: Liber Utbildning.

Trost, J. (1994) "Sam- och särboende parı, Fokus på familien, tidskrift for familiebehandling, årgång 22, nr 1, sid 47-56.

West, C. \& Zimmerman, D. (1987) „Doing Gender", Gender \& Society, 1, sid 125-151. 


\section{Summary}

\section{The family from the children's perspective}

The article emphasizes the importance of studying the family from the children's perspective and not, as so often happens, letting the family be treated from an adult perspective with the children as the recipients of care. The discussion is based on a project in which a group of children in the junior level worked on the theme of "My future family". The children drew pictures and wrote stories about events in a fictitious family. The project created a situation in which children were given the opportunity to fantasize and create family scenarios. These scenarios were analysed to see what sets of roles and role positions the children used. The aim was to capture children's conceptions about family relationships via their narratives. The article discusses the occurrence of different themes in the girls' and boys' narratives, the description of central actors, and the position of the narrator's alter ego. It also discusses how the children use narrative traditions and how conventions for linking time and place are used. We can observe that the girls to a greater extent than the boys mark a position of power for the woman/main person. The boys' narratives circumvent the strong, controlling pa- rental figure and thus give greater power to the children. From a generation perspective, this means that the boys describe family life as a life for children, while the girls describe it as a life in which children find themselves in a position of dependence. From a gender perspective it means that the girls explore the power of the woman in her capacity of being responsible for reproduction, while the boys make fun of power by describing a rather chaotic family life. At the same time, we can observe that there are variations within the boys' narratives and the girls' narratives and that care and responsibility for other people over a lengthy period can be treated in different ways. In the analysis of family scenarios we can grasp something of the children's way of relating to the family and the power relations and dependencies associated with it. The narratives can be read as fictions in which the narrator's own position is tested. A subtext in both boys' and girls' narratives is the family as an arena where different relations of care, control, play and expansivity are tried out. The family theme highlights ties between people and boundaries against the unknown, which both protect and can be transgressed. 